\title{
A Research on Public Space Planning of Rural Architecture Based on Villagers' Perception: A Case Study of Xingjing Town, Xixia District, Yinchuan City, Ningxia Province
}

\author{
Lyu Gui-fen ${ }^{1 *}$ \\ ${ }^{1}$ Ningxia College of Construction,355 Xueyuan East Road, Xixia District, Yinchuan City, Ningxia Hui Autonomous Region, 750021, \\ China
}

\begin{abstract}
In the context of rapid global urbanization, rural villagers' demand for public space is increasing. This article understands the development of rural public space through the perception of villagers. Using literature research method, questionnaire survey method, field investigation method and other methods, the investigation results of villagers' behavior in rural public spaces and villagers' satisfaction were analyzed. The study found that the villagers' demand for public space is mostly in terms of accessibility, good landscape, and good environment. The villagers hope that the town can have more public spaces to enrich life. Therefore, based on the conclusions of villagers' perception survey and research, this article studies the planning and design strategies of rural architecture public spaces.
\end{abstract}

\section{Research Background}

In the context of rapid global urbanization, the demand for relaxation of rural villagers has increased. The construction of rural public space improves the living environment while meeting the spiritual enjoyment and leisure needs of the villagers. The needs of villagers' spiritual and cultural life need to be met through development and the public space of the village, which is also the necessary prerequisite for the construction of a stable spatial structure of the countryside. By investigating villagers' satisfaction with rural public spaces, the factors affecting villagers' satisfaction as well as the villagers' leisure needs and focus are known, which will help the rational layout and improvement of rural public spaces and improve the quality of villagers' leisure life.

\section{Research methods and concepts}

\subsection{Research methods}

Through literature review to understand the research results of rural public space satisfaction, field surveys on the types and functions of public spaces in Xingjing Town, and at the same time, through questionnaire surveys to analyze villagers' leisure behavior in public spaces and their satisfaction with public spaces. It is mainly distributed to villagers who are engaged in leisure activities in villages and towns and nearby villagers. A total of 70 questionnaires were sent out, and 63 were effective, with an effective rate of $90 \%$. The questionnaire consists of three parts. The first is the basic attributes of interviewees. Second, the behavior of the interviewees in public space for leisure. The third is the satisfaction survey of respondents' perception of public space.

\subsection{Concepts}

The word "public space" appeared in 1950. Habermas believed that public space is "an activity space for citizens to discuss public affairs and participate in politics freely" [1]. There are also scholars who believe that pure public space provides a place for different groups to have freedom of activity and speech. Jacinta Francis and Bille Giles Corti proposed that public space is a meeting place where the masses can freely enter and promote the villagers to move together and increase the opportunities for communication [2]. The "acquaintance society" proposed by Fei Xiaotong in the Jiangcun study[3]. Huang Zongzhi and Du Zanqi made observations on the "same village" value standard in the North China Rural Research Institute [4,5]. Both show the role of public space in supporting rural social order and regulating the social actions of village members. Based on this, the public space studied in this article refers to various physical spaces and institutionalized organizational activities in society that have the nature of communication and undertake the functions of communication and contact.

\section{Research scope}

Xingjing Town is located on the outskirts of Xixia District, Yinchuan City, Ningxia. It was a Diaozhuang

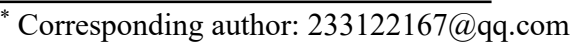


immigration town in the city that responded to the national immigration policy in 1983. It was moved from Jingyuan County, Ningxia. The Hui population accounts for $95 \%$ of the total population. It is an area where the minority population is concentrated. The town governs six villages. Most of the villagers live in the countryside, and a few live in the resettlement area in the town. The public space for villagers is mainly their own courtyard space, village activity center, small square and so on. The villagers like to go to the public space for leisure. The survey was conducted in the public space of the village. Figure 1 shows the small square of collective public space in the village. Figure 2 shows the entrance space of the village. Figure 3 shows the street space of the village.

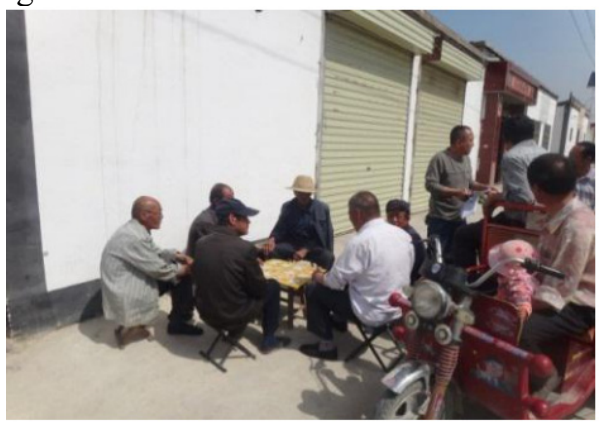

Fig. 1. Field survey: Village square

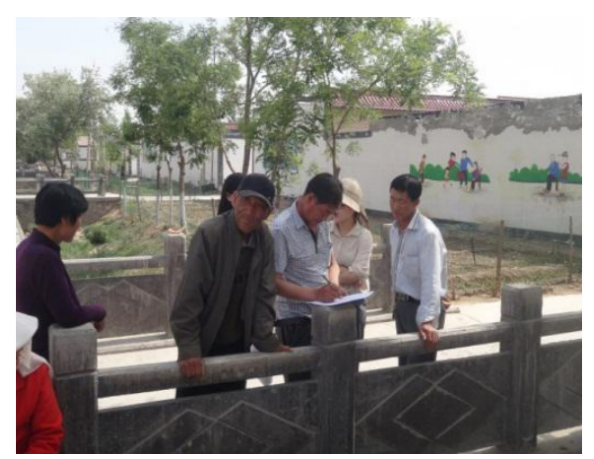

Fig. 2. Field survey: Entrance space

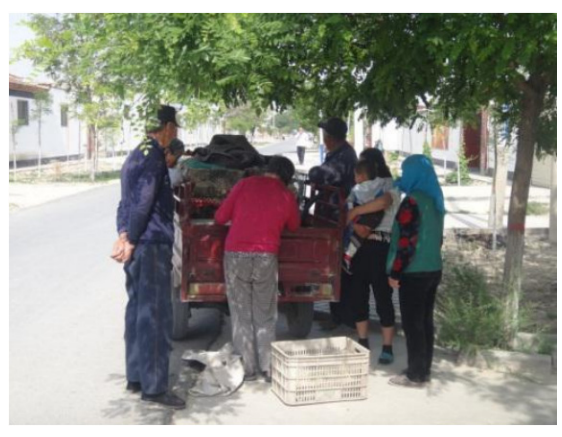

Fig. 3. Field survey: Street space

\section{Results and analysis}

\subsection{Characteristics of survey object}

In this survey, 21 men, accounting for $33.33 \%$, and 42 women, accounting for $66.67 \%$. 7 people under 18 years old, accounting for $11.11 \%$, 50 people between $18-30$ years old, accounting for $79.37 \%$, and 5 people aged 31 50 , accounting for $7.94 \%$. One person aged 51-60, accounting for $1.59 \%$. 11 persons with a high school degree or below, accounting for $17.46 \%, 7$ persons with a high school degree, accounting for $11.11 \%, 44$ persons with a college degree or above, accounting for $69.84 \%$, and 1 person with a master's degree or above, accounting for $1.59 \%$. 38 student occupations, accounting for $60.32 \%, 2$ teaching occupations, accounting for $3.17 \%, 6$ business people, accounting for $9.52 \%, 2$ laborers, accounting for $3.17 \%$, 5 agriculture, accounting for $7.94 \%$, and other occupations 10 People, accounting for $15.87 \%$. There are 51 people with an annual income of less than 5000, accounting for $80.95 \%$, and 4 people with an annual income of 5000-10000 yuan, accounting for $6.35 \%$. There are 8 people with an annual income of more than 10,000 yuan, accounting for $12.7 \%$. Through the analysis of the basic situation of the survey subjects, it is found that the survey subjects are mostly women, aged 18-30, college degree or above, and most of them are students with an annual income of less than 500 yuan.

\subsection{General situation of villagers' use of public space}

\subsubsection{Leisure purpose}

From the perspective of leisure purpose, $80.95 \%$ of villagers choose public space for rest (sitting, chatting, basking in the sun, enjoying the cool, walking the dog, playing with children, etc.). $60.32 \%$ of villagers are fitness (walking, jogging, various ball sports, roller skating, boxing, dancing, fitness equipment, etc.). $33.33 \%$ of villagers are games. $49.21 \%$ of villagers engage in interpersonal communication.

\subsubsection{Public space features}

Among the interviewed villagers, $50.79 \%$ of the villagers believe that the village has local characteristics. And think that the ancient mosque is the most likely landmark to represent the village. $71.43 \%$ of villagers hope that the creation of public space should focus more on functionality. $77.78 \%$ of villagers believe that the park square is currently the main leisure space. $53.97 \%$ of the villagers think it is a villager activity center.

\subsubsection{Leisure frequency, duration and period}

$63.49 \%$ of the villagers' daily leisure activities are mainly in their own courtyards. $61.9 \%$ of the villagers' daily leisure activities are the villagers' square (the square public space). $36.51 \%$ of villagers' daily leisure activities are at the entrance of the village (entrance public space). $23.81 \%$ of villagers' daily leisure activities are streets and lanes (street public spaces). Generally, the leisure time in the public space of the village is in the afternoon and $33.33 \%$ in the evening. On average, $65.08 \%$ of the villagers go to the public space of the village to carry out activities 1-2 times a day. 


\subsection{Villagers' satisfaction with existing public spaces}

The satisfaction survey questions involved 24 indicators such as environmental perception, psychological perception, and satisfaction. The questionnaire survey sets up 5 evaluation levels for each indicator, namely very satisfied, satisfied, fair, dissatisfied and very dissatisfied. There are a total of 24 questions and 5 basic information questions, including the gender, age, education background, income, and occupation of the interviewee. To ensure the accuracy of the analysis, SPSS was used to test the reliability and validity of the returned valid questionnaires. The Cronbach's alpha coefficient of the total scale is 0.840. The alpha coefficient value of each subscale is between 0.8170.855 . Research data has shown that a higher credibility. According to the level classification method of the Likert scale, the villagers' leisure perception is divided into 5 levels from very weak to strong, which are represented by $1,2,3,4$, and 5 . If the villagers' perceived satisfaction with the public space is greater than 3 , it means that the villagers are satisfied with the leisure function of the leisure belt, otherwise they are dissatisfied.

Use SPSS software analysis to explore villagers' satisfaction with the perception of leisure space (Table 1). In terms of satisfaction, it can be seen that the greening and sanitation of public spaces have the lowest satisfaction value. The public space landscape and leisure facilities have the highest satisfaction value. The satisfaction value of traffic conditions, location of activity venues, entertainment facilities, fitness facilities, children's facilities, and facilities for the elderly is in the middle. More than $70 \%$ of the villagers hope that there will be more public space in the town. Therefore, it is necessary to analyze the problems and improvement measures in the public space from these aspects.

Table 1. Villagers' satisfaction with existing public spaces

\begin{tabular}{|c|c|c|c|c|c|}
\hline Research section & $\begin{array}{c}\text { Very } \\
\text { dissatisfied }\end{array}$ & Dissatisfied & General & Satisfaction & Very satisfied \\
\hline Traffic condition & $9.52 \%$ & $9.52 \%$ & $42.86 \%$ & $28.57 \%$ & $9.52 \%$ \\
\hline Landscape condition & $6.35 \%$ & $11.11 \%$ & $44.44 \%$ & $22.22 \%$ & $15.87 \%$ \\
\hline $\begin{array}{l}\text { Leisure facilities } \\
\text { condition }\end{array}$ & $7.94 \%$ & $7.94 \%$ & $49.21 \%$ & $20.63 \%$ & $14.29 \%$ \\
\hline Position condition & $7.94 \%$ & $7.94 \%$ & $46.03 \%$ & $23.81 \%$ & $14.29 \%$ \\
\hline Greening condition & $6.35 \%$ & $14.29 \%$ & $36.51 \%$ & $22.22 \%$ & $20.63 \%$ \\
\hline $\begin{array}{c}\text { Recreational } \\
\text { facilities condition }\end{array}$ & $9.52 \%$ & $12.7 \%$ & $42.86 \%$ & $20.63 \%$ & $14.29 \%$ \\
\hline Sanitation condition & $12.7 \%$ & $7.94 \%$ & $36.51 \%$ & $26.98 \%$ & $15.87 \%$ \\
\hline $\begin{array}{l}\text { Fitness facilities } \\
\text { condition }\end{array}$ & $7.94 \%$ & $14.29 \%$ & $41.27 \%$ & $19.05 \%$ & $17.46 \%$ \\
\hline $\begin{array}{l}\text { Children's facilities } \\
\text { condition }\end{array}$ & $11.11 \%$ & $12.7 \%$ & $41.27 \%$ & $17.46 \%$ & $17.46 \%$ \\
\hline $\begin{array}{l}\text { Facilities for the } \\
\text { elderly condition }\end{array}$ & $11.11 \%$ & $11.11 \%$ & $42.86 \%$ & $19.05 \%$ & $15.87 \%$ \\
\hline
\end{tabular}

\section{Research conclusions}

\subsection{Research conclusions}

Through the survey of villagers' needs, it is found that the villagers' needs for public space are mostly in terms of accessibility and good environment. The survey results for the purpose of leisure show that $63.4 \%$ of the villagers are more willing to go to the nearby green space in front of their houses. In addition, through the satisfaction survey, some villagers are also very concerned about the landscape, green environment, and sanitation of public spaces. If there is a place where they can play, have a clear line of sight, and have beautiful greenery, they are more willing to go outdoors. Through interviews, we understand that the villagers are eager for some new entertainment methods to enrich their lives.

\subsubsection{Public space enriches the lives of residents and improves residents' satisfaction.}

Through analysis and research, it is found that the residents as a whole are relatively satisfied with the landscape and entertainment facilities. In the questionnaire process, residents mentioned that they like to go to the square after tea and dinner. In summer, there will be many people every afternoon to night, which provides space for everyone to communicate. The public space of the square has gradually become the main leisure place for residents. 


\subsubsection{The problem of insufficient number and single types of leisure facilities is widespread.}

In the course of the questionnaire, residents mentioned that they like to go to the square for leisure after eating and drinking. Therefore, there will be a large number of people gathering. In this case, there may be insufficient fitness facilities, children's facilities, and facilities for the elderly.

\subsubsection{The leisure activities are not rich enough.}

Residents generally mentioned that there are fewer leisure activities on the square, mainly square dancing and children's amusement facilities, and fewer facilities for the elderly.

\subsection{Suggestion}

Therefore, it is necessary to adopt a strategy that suits local conditions and incorporate regional characteristics. According to the development requirements of different regions, make reasonable planning and design of public space construction. Avoid the problem of great unification and lack of characteristics, create a public space that not only meets the needs of the villagers, but also contains regional elements, and establish a good rural image.

The village lacks common space and cannot meet the living needs of residents. The following design schemes are proposed: renovate abandoned courtyards into squares and green spaces, build new public buildings and residential buildings, or reclaim them into cultivated land. Greening the street and lane space, renovating the environment, planting street trees, and hardening the road surface. Renovate the environment of the square, remove randomly piled waste, and increase the green area; newly build small amusement parks to provide residents with recreational places.

\subsubsection{Redesign on idle land.}

The original building does not meet the requirements of the new function, partial renovation can be carried out, and the space renovation can be carried out in accordance with the planning requirements. Abandoned houses and houses of poor construction quality shall be rationally renovated according to the principle of one household, one house and the villagers' willingness, demolish hidden buildings, and build new houses according to standards. Idle construction land that cannot be used within the village should be renovated and greened, as shown in figure 4 .

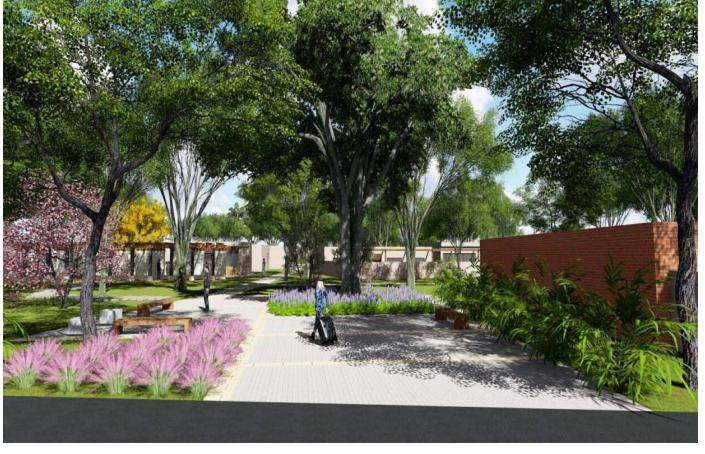

Fig. 4. Redesign on idle land.

\subsubsection{Street and lane design.}

Plant plants reasonably, use the effective space of streets and lanes, and make vertical greening and insert greenery. Strengthen the greening of courtyards, provide greening and shading of streets and lanes; harden the pavement of streets and lanes. As shown in figure 5, beautify the street and lane interface through the renovation of the building interface.

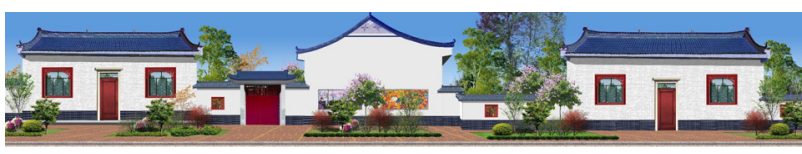

Fig. 5. Street and lane design.

\subsubsection{New design small garden.}

Plan to use the idle land of existing villages to set up residents' leisure squares. Set up a land with an area of no less than 200 square meters in each village group, combined with the green landscape, to provide villagers with a place for sports activities, as shown in figure 6 .

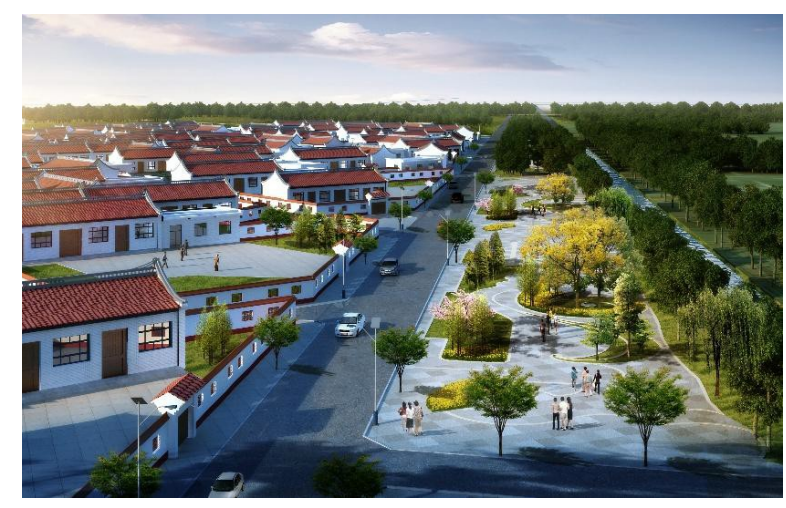

Fig. 6. New design small garden.

\section{Acknowledgement}

${ }^{*}$ This article is the research result of the scientific research project of Ningxia colleges and universities "Based on the rural revitalization strategy-based research on the integration planning of production and township in Xingjing Town, Xixia District, Yinchuan City" (No. NGY2018-223) 


\section{References}

1. ALTMAN I, ZUBE E. Public Places and Spaces (Vol. 10) [M]. New York: Plenum Press, 1989.

2. Xiaotong Fei, University of California Press, From the Soil: The Foundations of Chinese Society[M]. University of California Press, 1992

3. NEMETH J, SCHMIDT S. Toward a Methodology for Measuring the Security of Publicly Accessible Spaces[J]. Journal of the American Planning Association, 2007(73): 283-297.

4. FRANCIS J, CORTI B G, WOOD L, et al. Creating Sense of Community: the Role of Public Space[J]. Journal of Environmental Psychology, 2012(32): 401-409.

5. NADAI L. Discourses of Urban Public Space, USA 1960-1995 a Historical Critique[D]. New York: Columbia University, 2000. 